\title{
Associations of polymorphisms in NAT2 gene with risk and metastasis of osteosarcoma in young Chinese population
}

This article was published in the following Dove Press journal:

OncoTargets and Therapy

22 September 2015

Number of times this article has been viewed

\section{Zhengxiang Huang \\ Li Yuan ${ }^{2}$ \\ Zhenghui Jiang 3,4 \\ Dongliang Wang'}

'Department of Orthopedics, Xinhua Hospital, Shanghai Jiao Tong University School of Medicine, ${ }^{2}$ Department of Epidemiology, School of Public Health, Fudan University, Shanghai, ${ }^{3}$ Department of Orthopedics, The Second Affiliated Hospital of Zhejiang University School of Medicine, Hangzhou, ${ }^{4}$ Department of Orthopedics, The First People's Hospital of Wenling, Wenling, People's Republic of China
Correspondence: Dongliang Wang Department of Orthopedics, Xinhua Hospital, Shanghai Jiao Tong University School of Medicine, 1665 Kongjiang Road, Shanghai 200092, People's Republic of China

Tel +86 2l 25078899

Email wangdlxh@।63.com

\begin{abstract}
Osteosarcoma is the most common primary malignancy of bone in young individuals. Genetic factors may play an important role in the tumorigenesis of osteosarcoma. Here we carried out a case-control study to investigate seven NAT2 single-nucleotide polymorphisms (rs1799929, rs120, rs1041983, rs1801280, rs1799930, rs1799931, and rs1801279) on the risk and prognosis of osteosarcoma. This study included 260 young osteosarcoma cases and 286 controls. The TaqMan method was used to determine genotypes. We found that rs 1799931 $\mathrm{G}>\mathrm{A}$ polymorphisms were associated with a decreased risk of osteosarcoma in young Chinese population, and rs1041983 CT genotype seemed to play a protective role in the risk of osteosarcoma. However, further analysis showed that rs 1041983 polymorphisms were associated with an elevated risk of tumor metastasis, predicting poor prognosis. This study provided the first evidence for the associations between NAT2 polymorphisms and osteosarcoma risk and metastasis in Chinese population.
\end{abstract}

Keywords: osteosarcoma, NAT2, SNP, metastasis, susceptibility

\section{Introduction}

Osteosarcoma is the most common malignant tumor of bone in childhood and adolescence and is associated with early metastatic potential and a poor prognosis. ${ }^{1}$ Albeit the fact that quite a few studies on osteosarcoma are emerging these days, its tumorigenesis and roles that predict outcomes or malignancy risk are still poorly revealed. Genetic factors, such as single-nucleotide polymorphisms (SNPs), may play a role in the tumorigenesis and progression of osteosarcoma. Better understanding on genes factors is needed to identify the prognostic markers and therapeutic targets.

NAT2 gene encodes a Phase II xenobiotic-metabolizing enzyme. ${ }^{2}$ As a Phase II metabolizing enzyme, NAT2 catalyzes the metabolic activation of aromatic and heterocyclic amine carcinogens via $\mathrm{O}$-acetylation and $\mathrm{N}$-acetylation. Given that a single-nucleotide alteration causing substitution of amino acid residues may play a role in affecting the biological activity of the gene product, ${ }^{3}$ polymorphism in $N A T 2$ gene may be correlated with cancer risk and outcome.

A substantial number of researches on different ethnic populations have revealed that NAT2 alleles have an impact on the risk to a variety of malignancies, including acute lymphoblastic leukemia, ${ }^{4}$ lung squamous carcinoma, ${ }^{5}$ urinary bladder cancer, ${ }^{6}$ gastric cancer, ${ }^{7}$ and so on. However, to the best of our knowledge, there is still no study on the correlation between NAT2 polymorphisms and osteosarcoma incidence. Assuming that osteosarcoma risk can be linked to ionizing radiation exposure, it is plausible that genetic alterations in NAT2 gene may modulate osteosarcoma incidence. 
Hence, we launched a project on NAT2 polymorphisms in children and teenaged osteosarcoma patients in four institutions in 2007, in order to unveil the puzzle that whether NAT2 polymorphisms were associated with osteosarcoma incidence and risk of tumor metastasis in young-aged individuals. In this case-control study, we performed genotyping analyses of seven NAT2 tagging SNPs in 260 osteosarcoma patients and 286 controls in East China population, who share similar diet customs and living environment.

\section{Materials and methods Ethics approval}

This case-control study was approved by the Ethics Committees of four institutions (Xinhua Hospital, The Second Affiliated Hospital of Zhejiang University School of Medicine, The First People's Hospital of Wenling, and Fudan University) and was performed according to the Declaration of Helsinki. Informed consents were obtained from all participants or their guardians involved in the study.

\section{Study subject}

This study included 260 newly diagnosed osteosarcoma cases under the age of 20 years and 280 cancer-free controls, in the period between February 2007 and March 2012. All individuals involved in this study were specified as Chinese Han people. Diagnosis was confirmed by histopathological examination before radiotherapy and chemotherapy. All the included osteosarcoma cases underwent proper surgical operations by experienced surgeons, as well as nonsurgical therapeutic regimens according to the protocol. Detailed information such as tumor location and stage of osteosarcoma was obtained from medical records. All included patients were followed up regularly from the time of diagnosis for at least 36 months. The cancer-free controls were all recruited from trauma-induced fracture cases and were matched to osteosarcoma subjects by age and sex. Samples of $10 \mathrm{~mL}$ venous blood were obtained from each individual, and tumor tissues were conserved in liquid nitrogen.

\section{DNA isolation}

DNA was isolated from blood samples, which were collected into EDTA tubes, by using standard phenol-chloroform extraction and ethanol precipitation. DNA Blood Mini Kit (Qiagen, Berlin, Germany) was also used to isolate genomic DNA. As blood samples of 16 osteosarcoma patients were lost in an accident, corresponding tissue samples were used to extract DNA, with proteinase $\mathrm{K}$ digestion followed by phenol-chloroform extraction.

\section{SNP selection and genotyping}

Seven SNPs were selected in this study, that is, NAT2 rs1799929, rs120, rs1041983, rs1801280, rs1799930, rs1799931, and rs1801279. Date collection was conducted utilizing the Sequence Detection Software on an ABI StepOnePlus System (Thermo Fisher Scientific, Waltham, MA, USA). TaqMan primers and probes were designed using the ABI Assay-by-Design custom service. Samples were performed in triplicate and averaged. Genotyping results were validated by repeating once more. Amplification conditions on $\mathrm{ABI}$ StepOnePlus were as follows: $95^{\circ} \mathrm{C}$ for 10 minutes, followed by 40 cycles at $95^{\circ} \mathrm{C}$ for 15 seconds, and at $60^{\circ} \mathrm{C}$ for 60 seconds. The completed PCR plates were read with the ABI software. Laboratory personnel were blinded to the case-control status. NAT2 alleles were identified according to the Human NAT2 Alleles (Haplotypes) (http://nat.mbg. duth.gr/Human\%20NAT2\%20alleles_2013.htm).

\section{Statistical analysis}

The $\chi^{2}$ test was used to evaluate the differences in distributions of subject characteristics, selected variables, and genotypes of NAT2 variants between the osteosarcoma cases and controls. Odds ratios (ORs) and 95\% confidence intervals (CIs) were calculated to estimate the associations between the seven SNPs and the risk of osteosarcoma. Crude ORs were computed using logistic regression analyses, and adjusted ORs were adjusted for age and sex. The Hardy-Weinberg equilibrium for SNPs was tested with the Pearson's $\chi^{2}$ test. All statistical analyses were two-sided, and $P<0.05$ was considered as statistically significant. SPSS software (v.21.0; IBM Corporation, Armonk, NY, USA) was used to perform all analyses above.

\section{Results \\ Clinical features}

Clinical features of the included individuals are shown in Table 1. In this study, 260 young osteosarcoma cases and 286 controls were included. The median age of the 260 cases (151 males and 109 females) was 15.90 years (6-20) and that of controls was 16.24 years. All malignancies were graded according to Enneking GTM system. ${ }^{8}$ Differences in age and sex did not show statistical significance between two groups $(P=0.228$ and 0.559 , respectively).

\section{Associations between NAT2 tagging polymorphisms and risk of osteosarcoma} The seven candidate SNPs (rs1799929, rs1208, rs1041983, rs1801280, rs1799930, rs1799931, and rs1801279) and the incidence risk of osteosarcoma are shown in Table 2. 
Table I General characteristics of the subjects

\begin{tabular}{llll}
\hline Variables & $\begin{array}{l}\text { Osteosarcoma } \\
\text { cases [n (\%)] }\end{array}$ & $\begin{array}{l}\text { Control } \\
{[\mathbf{n}(\%)]}\end{array}$ & P-value \\
\hline $\begin{array}{l}\text { Age } \\
\quad \text { Mean } \pm \text { SD (year) }\end{array}$ & $15.90 \pm 3.37$ & $16.24 \pm 3.30$ & 0.228 \\
$\begin{array}{l}\text { Sex } \\
\quad \text { Male }\end{array}$ & $15 I(58.08)$ & $159(55.59)$ & 0.559 \\
$\quad \begin{array}{l}\text { Female } \\
\text { Location }\end{array}$ & $109(41.92)$ & $127(44.4 I)$ & \\
$\quad$ Trunk & $33(12.69)$ & & \\
$\quad$ Limbs & $227(87.31)$ & & \\
Enneking stages & & & \\
$\quad$ IA or IB & $4 I(15.76)$ & & \\
$\quad$ IIA or IIB or III & $219(84.24)$ & \\
Operation & & \\
$\quad$ Amputation & $53(20.38)$ & \\
Limb salvage & $207(79.62)$ & \\
Metastasis & & \\
$\quad$ Yes & $47(18.07)$ & \\
$\quad$ No & $213(8 I .93)$ & \\
\hline
\end{tabular}

Genotype distributions of all these SNPs were in the HardyWeinberg equilibrium in the control group $(P=0.295,0.063$, $0.115,0.205,0.216,0.081$, and 0.125 , respectively). In the single locus analyses, there was no statistically significant difference in genotype frequencies of NAT2 rs $1041983 \mathrm{C}>\mathrm{T}$ SNP between the cases and the controls $(P=0.081)$. When the $\mathrm{CC}$ homozygote genotype was used as the reference group, the CT genotype was associated with a decreased risk of osteosarcoma (CT versus CC: crude OR $=0.67$, 95\% CI $=0.47-0.96, P=0.029$; adjusted $\mathrm{OR}=0.68,95 \%$ $\mathrm{CI}=0.47-0.97, P=0.033$ ), whereas the TT genotype was not related to the risk of osteosarcoma (TT versus CC: crude $\mathrm{OR}=0.94,95 \% \mathrm{CI}=0.54-1.63, P=0.816)$. In the dominant model, a borderline statistical difference was found between $\mathrm{CT} / \mathrm{TT}$ variants with a decreased risk of osteosarcoma when compared with the rs $1041983 \mathrm{CC}$ genotype (CT/TT versus CC: crude $\mathrm{OR}=0.72,95 \% \mathrm{CI}=0.51-1.01, P=0.057$; adjusted $\mathrm{OR}=0.72,95 \% \mathrm{CI}=0.51-1.02, P=0.062)$. In the recessive model, when rs $1041983 \mathrm{CC} / \mathrm{CT}$ genotypes were used as the reference group, no statistical significance was shown between the TT homozygote genotype and the risk of osteosarcoma.

Statistical significance was revealed in genotype frequencies of NAT2 rs $1799931 \mathrm{G}>$ A SNP between the cases and the controls $(P=0.035)$. The GA genotype was found to be associated with a decreased risk of osteosarcoma when GG homozygote genotype was used as the reference group (GA versus GG: crude $\mathrm{OR}=0.64,95 \% \mathrm{CI}=0.45-0.91, P=0.014$; adjusted $\mathrm{OR}=0.65,95 \% \mathrm{CI}=0.45-0.93, P=0.017)$, whereas the AA homozygote genotype was not associated with osteosarcoma risk. In the dominant model, statistical difference was found between GA/AA variants with the risk of osteosarcoma when compared with the rs $1799931 \mathrm{GG}$ genotype (GA/AA versus GG: crude $\mathrm{OR}=0.63,95 \% \mathrm{CI}=0.44-0.90, P=0.010$; adjusted $\mathrm{OR}=0.64,95 \% \mathrm{CI}=0.45-0.90, P=0.012)$. In the recessive model, no statistical significance was found between the AA homozygote genotype and the risk of osteosarcoma when GG/GA genotypes were used as the reference group.

The rest five SNPs (rs1799929, rs1208, rs1801280, rs199930, and rs1801279) were not associated with osteosarcoma susceptibility in young Chinese population.

\section{NAT2 rs I04 I 983 C >T SNP was associated with metastasis of osteosarcoma}

Clinical characteristics (location, stage, operation, and metastasis) of osteosarcoma were used to further investigate the relationship between SNPs and the incidence of osteosarcoma (Table 3). The genotype CT frequency of rs 1041983 in metastasis cases (59.57\%) was greater when compared to cases without tumor metastasis (37.09\%), and the difference in frequency distribution showed statistical significance $(P=0.010)$ With respect to location, stage, and operation, no statistical difference was revealed. The rest six SNPs showed no statistical significance with clinical factors of osteosarcoma. The confounding variables are listed in Table 4 .

\section{Discussion}

Basic researches on new preventive and therapeutic strategies, such as immunotherapy ${ }^{9,10}$ for osteosarcomas, are showing promising targets. Moreover, expanded studies on risk factors of osteosarcoma will enrich our knowledge. It is widely accepted that both genetic and environmental factors contribute to the tumorigenesis of malignancies, including osteosarcoma. The emerging findings of susceptibility loci and genes correlated with osteosarcoma in the past years have provided insight into the diagnosis of this disease. NAT2 is an important xenobiotic-metabolizing enzyme, and NAT2 gene polymorphisms may be associated with the risk of malignancies as xenobiotics such as radiation, smoking, and alcohol use may induce carcinogenesis. ${ }^{11,12}$

In this case-control study of osteosarcoma, we found that NAT2 rs1799931 G>A SNP was associated with a decreased risk of osteosarcoma. A borderline statistical difference was found in genotype frequencies of NAT2 rs1041983 C > T SNP between the cases and the controls. Furthermore, we analyzed the association of SNPs with some clinical parameters, including age, sex, tumor location, enneking grade, operation, and metastasis. We demonstrated that albeit the result that rs 1041983 had a trend to be a protective factor 
Table 2 Logistic regression analyses of correlations between NAT2 rs I799929 C >T, rs I 208 A > G, rs I04I983 C>T, rs I80I280 T>C, rsI799930 G>A, rs I79993I G>A, and rs I80I279 G>A polymorphisms and risk of osteosarcoma

\begin{tabular}{|c|c|c|c|c|c|c|c|c|}
\hline \multirow[t]{2}{*}{ NAT2 genotype } & \multicolumn{2}{|c|}{ Cases $(n=266)$} & \multicolumn{2}{|c|}{$\begin{array}{l}\text { Controls } \\
(n=280)\end{array}$} & \multirow[t]{2}{*}{$\begin{array}{l}\text { Crude OR } \\
(95 \% \mathrm{Cl})\end{array}$} & \multirow[t]{2}{*}{$P$-value } & \multirow[t]{2}{*}{$\begin{array}{l}\text { Adjusted OR } \\
(95 \% \mathrm{Cl})\end{array}$} & \multirow[t]{2}{*}{$P$-value } \\
\hline & \multicolumn{2}{|l|}{$\mathbf{n} \%$} & \multicolumn{2}{|l|}{$\mathrm{n} \%$} & & & & \\
\hline \multicolumn{9}{|c|}{ NAT2 rs $1799929 \mathrm{C}>\mathrm{T}$} \\
\hline $\mathrm{CC}$ & 236 & 90.77 & 254 & 88.81 & 1.00 & & 1.00 & \\
\hline $\mathrm{CT}$ & 20 & 7.69 & 30 & 10.49 & $0.72(0.40-1.30)$ & 0.272 & $0.72(0.40-\mid .3 I)$ & 0.283 \\
\hline TT & 4 & 1.54 & 2 & 0.70 & $2.15(0.39-11.86)$ & 0.379 & $2.21(0.40-12.22)$ & 0.363 \\
\hline $\mathrm{CT}+\mathrm{TT}$ & 24 & 9.23 & 32 & 11.19 & $0.8 I(0.46-\mid .4 I)$ & 0.452 & $0.8 \mathrm{I}(0.46-\mid .43)$ & 0.470 \\
\hline $\mathrm{CC}+\mathrm{CT}$ & 256 & 98.46 & 284 & 99.30 & 1.00 & & 1.00 & \\
\hline TT & 4 & 1.54 & 2 & 0.70 & $2.22(0.40-12.22)$ & 0.360 & $2.29(0.4 I-12.62)$ & 0.343 \\
\hline \multicolumn{9}{|l|}{ NAT2 rsl208 A>G } \\
\hline AA & 248 & 95.38 & 272 & 95.10 & 1.00 & & 1.00 & \\
\hline AG & 9 & 3.46 & 13 & 4.55 & $0.76(0.32-I .8 I)$ & 0.534 & $0.7 \mid(0.29-I .69)$ & 0.434 \\
\hline GG & 3 & 1.15 & I & 0.35 & $3.29(0.34-31.84)$ & 0.304 & $3.08(0.32-29.94)$ & 0.333 \\
\hline$A G+G G$ & 12 & 4.62 & 14 & 4.90 & $0.94(0.43-2.07)$ & 0.878 & $0.87(0.39-1.94)$ & $0.74 I$ \\
\hline$A A+A G$ & 257 & 98.85 & 285 & 99.65 & 1.00 & & 1.00 & \\
\hline GG & 3 & 1.15 & I & 0.35 & $3.33(0.34-32.18)$ & 0.299 & $3.13(0.32-30.47)$ & 0.325 \\
\hline \multicolumn{9}{|c|}{ NAT2 rs $1041983 \mathrm{C}>\mathrm{T}$} \\
\hline $\mathrm{CC}$ & 120 & 46.15 & 109 & 38.11 & 1.00 & & 1.00 & \\
\hline CT & 107 & 41.15 & 145 & 50.77 & $0.67(0.47-0.96)^{*}$ & $0.029 *$ & $0.68(0.47-0.97)^{*}$ & $0.033^{*}$ \\
\hline TT & 33 & 12.69 & 32 & 11.19 & $0.94(0.54-1.63)$ & 0.816 & $0.93(0.54-1.62)$ & 0.803 \\
\hline $\mathrm{CT}+\mathrm{TT}$ & 140 & 53.85 & 177 & 61.89 & $0.72(0.5 \mathrm{I}-1.0 \mathrm{I})$ & 0.057 & $0.72(0.5 I-I .02)$ & 0.062 \\
\hline $\mathrm{CC}+\mathrm{CT}$ & 227 & 87.31 & 254 & 88.81 & 1.00 & & 1.00 & \\
\hline TT & 33 & 12.69 & 32 & 11.19 & $1.15(0.69-1.94)$ & 0.588 & $1.15(0.68-1.93)$ & 0.610 \\
\hline \multicolumn{9}{|c|}{ NAT2 $\mathrm{rs} \mid 80 \mathrm{I} 280 \mathrm{~T}>\mathrm{C}$} \\
\hline TT & 238 & 91.54 & 247 & 86.36 & 1.00 & & 1.00 & \\
\hline $\mathrm{TC}$ & 20 & 7.69 & 36 & 12.59 & $0.58(0.32-1.02)$ & 0.060 & $0.59(0.33-1.05)$ & 0.070 \\
\hline $\mathrm{CC}$ & 2 & 0.77 & 3 & 1.05 & $0.69(0.12-4.18)$ & 0.688 & $0.72(0.12-4.35)$ & 0.717 \\
\hline $\mathrm{TC}+\mathrm{CC}$ & 22 & 8.46 & 39 & 13.64 & $0.59(0.34-1.02)$ & 0.057 & $0.60(0.34-1.04)$ & 0.068 \\
\hline $\mathrm{TT}+\mathrm{TC}$ & 258 & 99.23 & 283 & 98.95 & 1.00 & & 1.00 & \\
\hline $\mathrm{CC}$ & 2 & 0.77 & 3 & 1.05 & $0.73(0.12-4.4 I)$ & 0.733 & $0.76(0.12-4.61)$ & 0.763 \\
\hline \multicolumn{9}{|c|}{ NAT2 rs $1799930 \mathrm{G}>\mathrm{A}$} \\
\hline GG & 158 & 60.77 & 167 & 58.39 & 1.00 & & 1.00 & \\
\hline GA & 73 & 28.08 & 98 & 34.27 & $0.79(0.54-1.14)$ & 0.209 & $0.79(0.54-1.14)$ & 0.210 \\
\hline AA & 29 & 11.15 & 21 & 7.34 & $1.46(0.80-2.67)$ & 0.218 & $1.50(0.82-2.74)$ & 0.191 \\
\hline $\mathrm{GA}+\mathrm{AA}$ & 102 & 36.15 & 119 & 41.61 & $0.91(0.64-1.28)$ & 0.572 & $0.91(0.65-1.28)$ & 0.593 \\
\hline $\mathrm{GG}+\mathrm{GA}$ & 231 & 88.85 & 265 & 92.66 & 1.00 & & 1.00 & \\
\hline AA & 29 & 11.15 & 21 & 7.34 & $1.58(0.88-2.85)$ & 0.126 & $1.62(0.90-2.94)$ & 0.109 \\
\hline \multicolumn{9}{|c|}{ NAT2 rsI79993। G>A } \\
\hline GG & 177 & 68.08 & 164 & 57.34 & 1.00 & & 1.00 & \\
\hline GA & 77 & 29.62 & 112 & 39.16 & $0.64(0.45-0.91)^{*}$ & $0.014^{*}$ & $0.65(0.45-0.93)^{*}$ & $0.017^{*}$ \\
\hline AA & 6 & 2.31 & 10 & 3.50 & $0.56(0.20-1.56)$ & 0.266 & $0.54(0.19-1.52)$ & 0.242 \\
\hline $\mathrm{GA}+\mathrm{AA}$ & 83 & 31.92 & 122 & 42.66 & $0.63(0.44-0.90)^{*}$ & $0.010^{*}$ & $0.64(0.45-0.90)^{*}$ & $0.012^{*}$ \\
\hline $\mathrm{GG}+\mathrm{GA}$ & 254 & 97.69 & 276 & 96.50 & 1.00 & & 1.00 & \\
\hline AA & 6 & 2.31 & 10 & 3.50 & $0.65(0.23-1.82)$ & 0.414 & $0.63(0.22-1.75)$ & 0.373 \\
\hline \multicolumn{9}{|c|}{ NAT2 rsI80I279 G $>$ A } \\
\hline GG & 251 & 96.54 & 270 & 94.41 & 1.00 & & 1.00 & \\
\hline GA & 8 & 3.08 & 15 & 5.24 & $0.57(0.24-1.38)$ & 0.213 & $0.59(0.24-\mid .4 I)$ & 0.236 \\
\hline AA & 1 & 0.38 & I & 0.35 & $1.08(0.07-17.29)$ & 0.959 & $1.21(0.08-19.61)$ & 0.892 \\
\hline $\mathrm{GA}+\mathrm{AA}$ & 9 & 3.46 & 16 & 5.59 & $0.61(0.26-1.40)$ & 0.238 & $0.63(0.27-1.44)$ & $0.27 I$ \\
\hline $\mathrm{GG}+\mathrm{GA}$ & 259 & 99.62 & 285 & 99.65 & 1.00 & & 1.00 & \\
\hline $\mathrm{AA}$ & I & 0.38 & I & 0.35 & $1.10(0.07-17.68)$ & 0.946 & $1.24(0.08-20.10)$ & 0.878 \\
\hline
\end{tabular}

Notes: ORs were adjusted for age and sex. *Statistically significant $(P<0.05)$.

Abbreviations: $\mathrm{Cl}$, confidence interval; OR, odds ratio. 
Table 3 Association between genotype frequencies of rs 1041983 and clinical features in osteosarcoma cases

\begin{tabular}{|c|c|c|c|c|c|}
\hline Variables & $\mathbf{n}$ & CC & CT & TT & $P$-value \\
\hline \multicolumn{6}{|l|}{ Location } \\
\hline Trunk & 33 & $13(39.39)$ & $16(48.48)$ & $4(12.12)$ & 0.645 \\
\hline Limbs & 227 & $107(47.14)$ & 91 (40.09) & $29(12.78)$ & \\
\hline \multicolumn{6}{|l|}{ Enneking stages } \\
\hline IA or IB & 41 & $21(51.22)$ & I3 (3I.7I) & 7 (I7.07) & 0.357 \\
\hline $\begin{array}{l}\text { IIA or IIB } \\
\text { or III }\end{array}$ & 219 & $99(45.21)$ & 94 (42.92) & $26(11.87)$ & \\
\hline \multicolumn{6}{|l|}{ Operation } \\
\hline Amputation & 53 & $30(56.60)$ & $19(35.85)$ & $4(7.55)$ & 0.181 \\
\hline Limb salvage & 207 & $90(43.48)$ & $88(42.5 I)$ & $29(14.01)$ & \\
\hline \multicolumn{6}{|l|}{ Metastasis } \\
\hline Yes & 47 & $17(36.2)$ & $28(59.57)$ & $2(4.26)$ & $0.010^{*}$ \\
\hline No & 213 & $103(48.36)$ & 79 (37.09) & $31(14.55)$ & \\
\hline
\end{tabular}

Notes: *Statistically significant $(P<0.05)$. Data presented as $n(\%)$.

in the risk of osteosarcoma, it was related to metastasis, predicting poor prognosis. Meanwhile, although rs1799931 played a protective role in carcinogenesis of osteosarcoma, it was not effective specifically to cases with different ages, sex, locations, grades, operations, and metastasis. These findings indicated that NAT2 was playing multifaceted roles in carcinogenesis and progression of osteosarcoma. This is the first research on associations between NAT2 polymorphisms and osteosarcoma in young Chinese population. Although the possible mechanisms of NAT2 affecting the tumorigenesis of osteosarcoma have barely been studied, we provided the evidence that NAT2 gene was related to osteosarcoma.

There are several studies on NAT2 SNPs and malignancy risk, providing different results. In researches on lung cancer, NAT2 rs1799930 G>A SNP was revealed to have a protective role in resisting lung squamous carcinoma in Chinese smokers. ${ }^{5}$ NAT2 gene polymorphism was also found to be associated with the risk of development of acute lymphocytic leukemia in Egyptian children. ${ }^{4}$ A meta-analysis on rs1799930 and rs1799931 polymorphisms with the risk of multiple types of cancer demonstrated that NAT2 rs1799930 was associated with an elevated risk of cancer in Asian, whereas NAT2 rs1799931 polymorphism was a protective factor against cancer development. ${ }^{13}$ There were also negative

Table 4 Confounding variables

\begin{tabular}{|c|c|c|c|}
\hline $\begin{array}{l}\text { Confounding } \\
\text { variables }\end{array}$ & $\begin{array}{l}\text { Metastasis } \\
\text { cases (n [\%]) }\end{array}$ & $\begin{array}{l}\text { Nonmetastasis } \\
\text { cases (n [\%]) }\end{array}$ & $P$-value \\
\hline \multicolumn{4}{|l|}{ Age } \\
\hline Mean $\pm S D$ (year) & $15.68 \pm 3.48$ & $15.95 \pm 3.35$ & 0.623 \\
\hline \multicolumn{4}{|l|}{ Sex } \\
\hline Male & $29(61.70)$ & I $22(57.28)$ & \\
\hline Female & I8 (38.30) & 91 (42.72) & 0.578 \\
\hline
\end{tabular}

results in studies on prostate cancer in Slovak population, ${ }^{14}$ esophageal cancer in Chinese population, ${ }^{15}$ and breast cancer in Lebanese women. ${ }^{16}$ Varied results in different ethnic populations call for further studies to investigate NAT2 polymorphisms in different malignancies.

Gene factors, such as epigenetic mechanisms and recurrent genomic rearrangements, play important roles in carcinogenesis and progression of osteosarcoma. ${ }^{17,18}$ SNPs were also revealed to be associated with susceptibility and prognosis of osteosarcoma in different ethnic populations, such as GRM4 gene, ${ }^{19}$ COL $1 A 1,{ }^{20}$ and $B M P-2 .{ }^{21}$ Albeit a rare malignancy, whose incidence is approximately 3-4 per million people, osteosarcoma is threatening the health of children and teenagers worldwide. More in-depth researches are in urgent need to unveil the elusive mechanisms of the development of osteosarcoma.

There are still several limitations in this case-control study. First, all the patients and controls were enrolled from three hospitals, and related inherent bias may have already affected our results. Second, the sample size in our study was moderate, which may limit the statistical power. Further replication studies are needed. We are collecting data from newly diagnosed cases to strengthen this project.

In summary, this study demonstrated that NAT2 rs1799931 polymorphism played a role in osteosarcoma resistance in young Chinese individuals. NAT2 rs1041983 polymorphism was related to metastasis of osteosarcoma, predicting poor prognosis.

\section{Disclosure}

The authors report no conflicts of interest in this work.

\section{References}

1. Picci P. Osteosarcoma (osteogenic sarcoma). Orphanet J Rare Dis. 2007;2:6

2. Hickman D, Pope J, Patil SD, et al. Expression of arylamine N-acetyltransferase in human intestine. Gut. 1998;42:402-409.

3. Shields PG, Harris CC. Cancer risk and low-penetrance susceptibility genes in gene-environment interactions. J Clin Oncol. 2000;18:2309-2315.

4. Kamel AM, Ebid GT, Moussa HS. N-Acetyltransferase 2 (NAT2) polymorphism as a risk modifier of susceptibility to pediatric acute lymphoblastic leukemia. Tumour Biol. 2015;36(8):6341-6348.

5. Tian F, Zhang Y, Ren Y, Shen L, Wu W, Zhou B. N-Acetyltransferase 2 (NAT2) gene polymorphism and exposure to smoking in lung cancer of Chinese males. Med Oncol. 2014;31:90.

6. Hein DW. N-acetyltransferase 2 genetic polymorphism: effects of carcinogen and haplotype on urinary bladder cancer risk. Oncogene. 2006; 25:1649-1658.

7. Yu J, Deng Y, Chen JP. N-acetyltransferase 2 status and gastric cancer risk: a meta-analysis. Tumour Biol. 2014;35:6861-6865.

8. Enneking WF. A system of staging musculoskeletal neoplasms. Clin Orthop Relat Res. 1986:9-24.

9. Li B, Zhu X, Sun L, et al. Induction of a specific CD8+ T-cell response to cancer/testis antigens by demethylating pre-treatment against osteosarcoma. Oncotarget. 2014;5:10791-10802. 
10. Huang G, Yu L, Cooper LJ, Hollomon M, Huls H, Kleinerman ES. Genetically modified $\mathrm{T}$ cells targeting interleukin- 11 receptor alphachain kill human osteosarcoma cells and induce the regression of established osteosarcoma lung metastases. Cancer Res. 2012;72:271-281.

11. Tamer L, Yilmaz A, Yildirim H, et al. N-acetyltransferase 2 phenotype may be associated with susceptibility to age-related cataract. Curr Eye Res. 2005;30:835-839.

12. Hernandez A, Xamena N, Gutierrez S, et al. Basal and induced micronucleus frequencies in human lymphocytes with different GST and NAT2 genetic backgrounds. Mutat Res. 2006;606:12-20.

13. Tian FS, Shen L, Ren YW, Zhang Y, Yin ZH, Zhou BS. N-acetyltransferase 2 gene polymorphisms are associated with susceptibility to cancer: a meta-analysis. Asian Pac J Cancer Prev. 2014;15:5621-5626.

14. Vilckova M, Jurecekova J, Dobrota D, etal. Variation in N-acetyltransferase 2 (NAT2), smoking and risk of prostate cancer in the Slovak population. Med Oncol. 2014;31:987.

15. Wang L, Tang W, Chen S, et al. N-acetyltransferase 2 polymorphisms and risk of esophageal cancer in a Chinese population. PLoS One. 2014; 9:e87783.
16. Zgheib NK, Shamseddine AA, Geryess E, et al. Genetic polymorphisms of CYP2E1, GST, and NAT2 enzymes are not associated with risk of breast cancer in a sample of Lebanese women. Mutat Res. 2013; 747-748:40-47.

17. Li B, Ye Z. Epigenetic alterations in osteosarcoma: promising targets. Mol Biol Rep. 2014;41:3303-3315.

18. Ribi S, Baumhoer D, Lee K, et al. TP53 intron 1 hotspot rearrangements are specific to sporadic osteosarcoma and can cause Li-Fraumeni syndrome. Oncotarget. 2015;6:7727-7740.

19. Jiang C, Chen H, Shao L, Dong Y. GRM4 gene polymorphism is associated with susceptibility and prognosis of osteosarcoma in a Chinese Han population. Med Oncol. 2014;31:50.

20. He M, Wang Z, Zhao J, Chen Y, Wu Y. COL1A1 polymorphism is associated with risks of osteosarcoma susceptibility and death. Tumour Biol. 2014;35:1297-1305.

21. Cong Y, Li CJ, Zhao JN, Liu XZ, Shi X. Associations of polymorphisms in the bone morphogenetic protein-2 gene with risk and prognosis of osteosarcoma in a Chinese population. Tumour Biol. 2015;36: 2059-2064.
OncoTargets and Therapy

\section{Publish your work in this journal}

OncoTargets and Therapy is an international, peer-reviewed, open access journal focusing on the pathological basis of all cancers, potential targets for therapy and treatment protocols employed to improve the management of cancer patients. The journal also focuses on the impact of management programs and new therapeutic agents and protocols on

\section{Dovepress}

patient perspectives such as quality of life, adherence and satisfaction The manuscript management system is completely online and includes a very quick and fair peer-review system, which is all easy to use. Visit http://www.dovepress.com/testimonials.php to read real quotes from published authors. 